

Scand J Work Environ Health 2012;38(5):391-392

https://doi.org/10.5271/sjweh.3315

Published online: 09 Aug 2012, Issue date: 01 Sep 2012

Is retirement beneficial or harmful to mental health?

by Härmä $M$

Affiliation: Finnish Institute of Occupational Health, Topeliuksenkatu 41 a A 00250 Helsinki, Finland. mikko.harma@ttl.fi

Refers to the following texts of the Journal: 2012;38(5):409-417

2011;37(6):451-453 2011;37(6):455-463 1997;23(6):403-413

The following article refers to this text: 2013;39(2):121-124

Key terms: antidepressant; disability; disability pension; editorial; mental health; old-age retirement; retirement; work ability

This article in PubMed: www.ncbi.nlm.nih.gov/pubmed/22878398 


\section{Is retirement beneficial or harmful to mental health?}

Work careers have been extended in many countries by lifting up the statutory old-age retirement age. Since it has been estimated that only about half of the workforce maintain work ability on a moderate level after some 63-65 years $(1,2)$ the discussion on an appropriate statutory retirement age has increased focus on the possible health effects of the transition to retirement. The discussion on possible changes in mental health has been especially interesting. Several recent prospective studies on workers' mental health trajectories prior and after transition to retirement seem to suggest that retirement could be beneficial for mental health (3-5), but the evidence is not consistent.

In this issue of the Scandinavian Journal of Work, Environment \& Health, Laaksonen et al (6) examined trajectories of mental health five years before and five years after both old-age and disability retirement using data on purchases of psychotropic drugs. The study included all employees from the City of Helsinki who had retired between 2000-2008. This new study is novel compared to earlier studies due to the examination of the association of mental health to both old-age retirement as well as permanent, partial, and temporary disability retirement. Also, the use of different psychotropic drug types at 3-month intervals was used as an objective indicator of time-related changes in mental health. The results show that old-age retirement was unrelated to purchases of psychotropic drugs, but there was a constant increase in the use of these drugs with no clear change at the time of the retirement. Among disability retirees, psychotropic medication increased steeply before retirement. After disability retirement, purchases of antidepressants decreased slightly, while those of hypnotics and sedatives increased. The changes were largest among those who retired due to mental disorders and among non-manual employees.

The steep increase in antidepressant use before disability retirement, as well as the modestly decreased use of them after retirement is in line with the results published by Oksanen et al (5) from the Finnish Public Sector Study. A new finding is that the steepest increase in the pre-retirement use of psychotropic drugs took place among the temporary retirement group. In Finland, insurance companies require a test period of pharmacological treatment before allowing disability retirement. Up to now, no similar requirements have been made for work modifications or other workplace-related interventions. Since the use of psychotropic medication increased already some five years before disability retirement, there should be several years time to consider interventions other than pharmacological ones. Based on prospective studies, increases in job control, social support, and communication in the working place are promising candidates to decrease the risk for disability pension (7-9). However, intervention studies related to work-related factors to prevent mental disorders among aging workers are very few $(10,11)$.

Based on the French GAZEL cohort, old-age retirement was associated with a substantial reduction in mental fatigue, depressive symptoms, and insomnia $(3,4)$. Similarly, the Finnish Public Sector Study reported a decrease in antidepressant use after retirement among old-age retirees (5). In the Laaksonen et al study, there was an overall steady increase in the purchases of all psychotropic drugs among old-age retirees consisting mainly of an increase in the use of hypnotics and sedatives and no change in the use of antidepressants. The discrepancies between the studies are rather surprising and are probably due to national or methodological differences. Some of the difference could be due to the age of the statutory retirees. The French statutory retirees were almost 10 years younger $-72 \%$ were $53-57$ years - while the old-age retirement age in the two Finnish studies was normally 63-65 years.

The subjects of the two Finnish studies represent municipal workers, and the samples are thus rather 
similar. However, data on the use of medication in the Laaksonen et al study (6) was collected from a later period (2000-2008) than the Oksanen et al study (5) (1994-2005). The latter also required the use of $\geq 30$ daily doses in each year in order to classify the use of antidepressant. Laaksonen et al (6) had a more sensitive measure for the use of the drugs by simply calculating the mean use of different type of psychotropic drugs during each of the 3-month intervals. The use of sedative antidepressants increased rapidly in Finland from 1999-2009 (12), and there has also been an increasing tendency to use smaller amounts of antidepressants for insomnia and anxiety disorders. It is thus plausible that the generally increased use of antidepressants in Finland could explain the non-decreasing steady trend in the use of antidepressants in the later study of Laaksonen et al (6).

Nevertheless, the results suggest that it is not always true that old-age retirement is beneficial to mental health. This obviously depends on work and health-related factors, disability retirement being most often beneficial for workers with mental disorders. In some cases, the workplace can be a valuable resource-building environment for mental health (13).

\section{References}

1. Härmä M. Adding more years to the work careers of an aging workforce - what works? Scand J Work Environ Health. 2011;37(6):451-3. http://dx.doi.org/10.5271/sjweh.3198.

2. von Bonsdorff, ME, Kokko K, Seitsamo J, von Bonsdorff MB, Nygård C-H, Ilmarinen J, Rantanen T. Work strain in midlife and 28-year work ability trajectories. Scand J Work Environ Health. 2011;6:455-463. http://dx.doi.org/10.5271/ sjweh.3177.

3. Westerlund H, Vahtera J, Ferrie JE, Singh-Manoux A, Pentti J, Melchior M, et al. Effect of retirement on major chronic conditions and fatigue: French GAZEL occupational cohort study. BMJ. 2010;341:c6149. http://dx.doi.org/10.1136/ bmj.c6149.

4. Vahtera J, Westerlund H, Hall M, Sjösten N, Kivimäki M, Salo P, et al. Effect of retirement on sleep disturbances: the GAZEL prospective cohort study. Sleep. 2009;32:1459-66.

5. Oksanen T, Vahtera J, Westerlund H, Pentti J, Sjösten N, Virtanen M, et al. Is Retirement Beneficial for Mental Health?: Antidepressant Use Before and After Retirement. Epidemiology. 2011;22:553-9. http://dx.doi.org/10.1097/ EDE.0b013e31821c41bd.

6. Laaksonen M, Metsä-Simola N, Martikainen P, Pietiläinen O, Rahkonen O, Gould R, Partonen T, Lahelma E. Trajectories of mental health before and after old-age and disability retirement: a register-based study on purchases of psychotropic drugs. Scand J Work Environ Health. 2012;38(5):409-417. http://dx.doi.org/10.5271/sjweh.3290.

7. Krause N, Lynch J, Kaplan GA, Cohen RD, Goldberg DF, Salonen JT. Predictors of disability retirement. Scand J Work Environ Health. 1997;23:403-13. http://dx.doi.org/10.5271/sjweh.262.

8. Vahtera J, Laine S, Virtanen M, Oksanen T, Koskinen A, Pentti J and Kivimaki M. Employee control over working times and risk of cause-specific disability pension: the Finnish Public Sector Study. Occup Environ Med. 2010;67:479-485. http:// dx.doi.org/10.1136/oem.2008.045096.

9. Korkstad S, Johsen R, Westin S. Social determinants of disability pension: a 10-year follow-up of 62000 people in a Norwegian county population. Int J Epidemiol. 2002;31:1183-92. http://dx.doi.org/10.1093/ije/31.6.1183.

10. Lagervels SE, Bultmann U, Franche RL, van Dijk FJH, Vlasveld MMC, van der Feltz-Cornelis CM, Bruinvels DJ, Huijs JJJM, Blonk RWB, vander Klink JJL, Nieuewenhuijsen K. Factors associated with work participation and work functioning in depressed workers: a systematic review. J Occup Rehabil 2010:275-292. http://dx.doi.org/10.1007/s10926-009-9224-x.

11. McDermott HJ, Kazi A, Munir F, Haslam C. Developing occupational health services for active age management. Occupational Medicine 2010;60:193-204. http://dx.doi.org/10.1093/occmed/kqq026.

12. Finnish Statistics on Medicines. Finnish Medicines Agency and Social Insurance Institution, Helsinki 2010.

13. Hakanen JJ, Schaufeli WB. Do burnout and work engagement predict depressive symptoms and life satisfaction? A three-wave seven-year prospective study. J Affect Disorder 2012 ([epub ahead of print]. http://dx.doi.org/10.1016/j. jad.2012.02.043.

Mikko Härmä, MD

Finnish Institute of Occupational Health

Topeliuksenkatu 41 a $\mathrm{A}$

00250 Helsinki

Finland

[E-mail: mikko.harma@ttl.fi] 